\title{
Promoção de saúde bucal na praia: um relato de experiência
}

\author{
Oral health promotion on the beach: an experience report
}

Promoción de la salud bucal en la playa: un informe de experiencia

Lukas Mendes de Abreu* Jacianny Laurindo Pereira², Thalia Franciele Barreto Cordeiro², Luana de Lima Poroca Almeida ${ }^{2}$, Ranielly de Souza Silva², Lisandre Letícia Gomes da Silva², Juliana Pessoa de Albuquerque Pinheiro ${ }^{2}$, João Artur Peixoto Granja ${ }^{2}$, Cláudia Nely Mendonça dos Santos $^{2}$, Renata Patrícia Freitas Soares de Jesus ${ }^{3}$.

\section{RESUMO}

Objetivo: Relatar a experiência do projeto de extensão Promoção de Saúde Bucal na Praia. Relato de experiência: O projeto de extensão "Promoção de Saúde Bucal na Praia" promoveu a saúde bucal de barraqueiros, vendedores ambulantes e pescadores, das praias do município de Recife. Por meio da educação em saúde fomentou-se a reflexão e o aprendizado, através de ações educativas, com palestras, rodas de conversas e panfletagem, nas praias, sobre patologias bucais relacionadas à exposição solar, seus fatores de riscos, como preveni-las e diagnosticá-las precocemente, enfatizando-se e ensinado a esses trabalhadores o auto exame da boca e hábitos saudáveis bucais e de vida. Considerações finais: As atividades realizadas tiveram repercussão positiva, tendo em vista que o público abordado era carente de informação e grande parte dele demonstrava interesse pelos conhecimentos repassados. Os trabalhadores relataram o desconhecimento acerca da existência da rede de atenção à saúde bucal e questionaram a falta de acessibilidade aos serviços odontológicos.

Palavras-chave: Promoção da saúde, Queilite, Carcinoma de células escamosas.

\begin{abstract}
Objective: To report the experience of the Oral Health Promotion on the Beach extension project. Experience report: The extension project "Promotion of Oral Health on the Beach" promoted the oral health of stallholders, street vendors and fishermen, from the beaches of the municipality of Recife. Through health education, reflection and learning were promoted through educational actions, with lectures, conversation circles and leafleting, on the beaches, about oral pathologies related to sun exposure, their risk factors, how to prevent them and diagnose them early, emphasizing and teaching these workers self-examination of the mouth and healthy oral and life habits. Final considerations: The activities carried out had a positive impact, considering that the public addressed was lacking in information and a large part of them showed interest in the knowledge passed on. The workers reported their lack of knowledge about the existence of the oral health care network and questioned the lack of accessibility to dental services.
\end{abstract}

Keywords: Health promotion, Cheilitis, Carcinoma, Carcinoma squamous cell.

\section{RESUMEN}

Objetivo: Informar la experiencia del proyecto de extensión Promoción de la salud bucal en la playa. Informe de experiencia: El proyecto de extensión "Promoción de la Salud Bucal en la Playa" promovió la salud bucal de los tenderos, vendedores ambulantes y pescadores, de las playas del municipio de Recife. A través de la educación para la salud, se promovió la reflexión y el aprendizaje a través de acciones educativas, con charlas, círculos de conversación y reparto de folletos, en las playas, sobre patologías bucales relacionadas con la exposición solar, sus factores de riesgo, cómo prevenirlas y diagnosticarlas precozmente, enfatizando y enseñándolas. autoexamen de la boca de los trabajadores y hábitos bucales y de vida saludables. Consideraciones finales: Las actividades realizadas tuvieron un impacto positivo, considerando que el público al que se dirigió carecía de información y una gran parte de ellos mostró interés por el conocimiento transmitido. Los trabajadores informaron su desconocimiento sobre la existencia de la red de atención de salud bucal y cuestionaron la falta de accesibilidad a los servicios dentales.

Palabras clave: Promoción de la salud, Queilitis, Carcinoma de células escamosas.

\footnotetext{
1 Universidade Estadual Paulista “Júlio de Mesquita Filho" (UNESP), Araçatuba - SP.

*E-mail: lukasabreu.m@gmail.com

2 Centro Universitário Tiradentes (UNIT), Recife - PE.

3 Universidade Federal de Pernambuco (UFPE), Recife - PE.
} 


\section{INTRODUÇÃO}

No Brasil, principalmente durante os meses de verão, as praias são invadidas por pessoas em busca de lazer e com elas outras, procurando fontes alternativas de renda básica ou complementar. A atividade comercial em praias urbanas é muito diversificada. O comércio formal é constituído por restaurantes e bares que se instalam as margens das praias e o comércio informal se instala preferencialmente na faixa de areia, o mais próximo possível dos usuários da praia, sendo realizado principalmente por barraqueiros, vendedores ambulantes e pescadores que não contam com qualquer plano de ordenamento ou gestão (ARAÚJO MCB e COSTA M, 2008).

É importante destacar que o comercio informal, têm a maior vulnerabilidade social, estão expostos a fatores de riscos, como a exposição solar, sujeitos a condições de trabalho precárias, sem apoio e assistência necessária (ARAÚJO MCBD, et al., 2012).

No Brasil, onde a exposição solar é intensa, o câncer de lábio assume uma grande importância, já que os raios solares constituem o principal fator de risco para o desenvolvimento do carcinoma epidermóide. Além disso, por se tratar de um país tropical, onde muitos cidadãos garantem o sustento de sua casa e suas famílias través de trabalho com exposição solar contínua, podendo gerar então danos irreversíveis, principalmente, associada ao não uso de fatores de proteção (ARAÚJO CP, et al., 2012).

Entre as doenças ocupacionais a que estes trabalhadores estão expostos destacam-se as patologias relacionadas com exposição solar, como a queilite actínica e o carcinoma epidermóide (NEVILLE N, et al., 2016). A queilite actínica refere-se a uma alteração crônica, pré-maligna, resultante da exposição solar frequente e prolongada, acometendo principalmente a região de lábio inferior, tendo uma maior predileção pelo gênero masculino e leucodermas (ARAÚJO CP, et al., 2012).

O carcinoma epidermóide é uma lesão neoplásica maligna originada do epitélio de revestimento, e consiste no quinto tumor maligno que mais acomete os homens. Sua maior prevalência ocorre entre a $5^{\circ}, 6^{\circ}$ e $7^{\circ}$ décadas de vida, em pessoas expostas aos fatores de riscos, como: radiação solar, tabagismo e etilismo (NOVAES TSG, et al., 2020).

Estudos realizados no litoral brasileiro têm mostrado a alta prevalência dessas lesões em barraqueiros, ambulantes e pescadores (LUCENA EEDS, 2011; QUEIROZ LR, 2016; MEDEIROS KF, 2017).Tais dados são preocupantes tendo em vista que conta-se que o diagnóstico do câncer bucal tem sido realizado tardiamente no Brasil a despeito das lesões iniciais, geralmente assintomáticas, não são valorizadas pelo próprio indivíduo e nem pelos profissionais de saúde, sugerindo falta de conhecimento da patologia, deficiência na procura de atendimento médica por parte do indivíduo e/ou do acesso e qualidade da assistência à saúde, fator este ligado a uma ausência de programas governamentais que visem à prevenção e de um sistema de saúde eficiente (DOS SANTOS LCO, DE MEDEIROS BATISTA O e CANGUSSU MCT, 2010).

A partir da constatação de que o câncer bucal é um problema de saúde pública, é importante que a população seja informada sobre a doença e os fatores de risco e como preveni-la e diagnosticá-la precocemente, enfatizando-se o autoexame da boca, que consiste de técnica simples que o próprio indivíduo é capaz de realizar com a finalidade de identificar lesões precursoras do câncer (QUIRINO MRDS, et al., 2013).

Sabendo que tais trabalhadores estão expostos a fatores de riscos, como a exposição solar, sujeitos a condições de trabalho precárias, sem apoio e assistência necessária, é sugerido uma proposta de intervenção através de ações sociais com a extensão dos conhecimentos adquiridos na faculdade para a população, promovendo assim uma melhoria na qualidade de vida desses trabalhadores para que continuem a desenvolver suas atividades laborais de forma segura e preventiva.

\section{RELATO DE EXPERIÊNCIA}

O Projeto de Extensão Universitária intitulado "Promoção de Saúde Bucal na Praia", sob supervisão de uma docente e de quatro acadêmicos do curso de odontologia, do 6o período, do Centro Universitário Tiradentes, foi desenvolvido através de ações educativas em Promoção de Saúde Bucal nas regiões 
litorâneas do município de Recife, estado de Pernambuco, no ano de 2018 com o objetivo principal de fomentar a reflexão e a aprendizagem sobre a saúde bucal por meio da educação em saúde com barraqueiros, vendedores ambulantes e pescadores, das praias do município de Recife, sobre patologias orais relacionadas à exposição solar e realizar a promoção da saúde bucal.

Primeiro foi feito um estudo observacional de campo para verificar como funcionava o trabalho do publico alvo, os locais, dias e horários. Foram organizadas 20 ações, em áreas especifica das praias de Recife, para que todos os locais e trabalhadores fossem contemplado com o projeto. Os quatros acadêmicos receberam um treinamento para realizar as ações, de modo que todos os integrantes do projeto ficassem calibrados quanto aos temas abordados e como as informações deveriam ser passadas.

Para auxiliar o entendimento desses trabalhadores foi confeccionado panfletos, com imagens autoexplicativas e com linguagem acessível para facilitar o entendimento do publico alvo, sobre as lesões relacionadas à exposição solar e o passo a passo para fazer o auto exame de boca.

Através de palestras e rodas de conversas, foram realizadas ações educativas, quanto aos hábitos saudáveis de vida e as patologias bucais relacionadas à exposição solar, quais eram essas patologias, os fatores de risco, como preveni-las e como diagnosticá-las precocemente.

Buscou-se sensibilizar e estimular a realização de atividades preventivas como o uso de equipamentos de proteção individual: boné, blusas de manga longa, protetor solar/labial, de modo que esses trabalhadores compreendessem que a melhor opção de tratamento para essas lesões é prevenção, autocuidado e autoexame, onde a conscientização da população é fundamental.

Foi enfatizando o auto exame da boca, que consiste de técnica simples, que o próprio indivíduo é capaz de realizar, com a finalidade de identificar lesões causas pela exposição solar e lesões precursoras do câncer, para isso foi levado espelhos, para facilitar e auxiliar o ensinamento desses trabalhadores a realizar esse auto exame.

As atividades que foram prestadas tiveram repercussões positivas diante o público abordado. Tendo em vista que a falta de informação e conhecimento diante dessas pessoas eram bastante comuns, porém, grande parte delas sempre demonstravam interesse pelas informações que eram passadas por todos os membros do projeto. O desconhecimento do público abordado acerca da existência de serviços voltados à saúde bucal foi bastante questionado.

Os trabalhadores contemplados pelo projeto relataram que não tinham acesso a determinados serviços. Declararam-se "esquecidos" pelo poder público e que apoiam iniciativas como a deste projeto, o qual tem o potencial de modificar o status desses indivíduos em relação a sua saúde oral e poder receber conhecimento de forma simples e coerente.

\section{DISCUSSÃO}

O Brasil é um país tropical com alta incidência de raios solares e possui uma grande quantidade de pessoas que exercem atividades ao ar livre. Os efeitos nocivos da radiação ultravioleta sobre a saúde têm sido demonstrados especialmente para aqueles indivíduos que são intensamente e continuamente expostos (TEIXEIRA ACDOC, et al., 2018).

A exposição constante ao sol pode causar danos irreparáveis, principalmente se ocorrer nos horários de maior incidência dos raios solares sem a devida proteção, pois o efeito cumulativo da radiação sobre os tecidos humanos pode levar ao desenvolvimento de lesões como a queilite actínica e sua posterior evolução para o carcinoma de células escamosas de lábio (RODRIGUES F, et al., 2016).

Em estudo recente, Barros CC, et al. (2020), classificam a queilite actínica como a segunda lesão mais frequente em lábio. Dessa forma, é evidente a importância que essa lesão representa, principalmente em regiões tropicais onde a população se expõe de forma crônica aos raios solares, devido a atividades laborais ao ar livre (DANCYGER A, et al., 2018).

A queilite actínica é uma desordem potencialmente maligna, associada à exposição crônica à luz UV, que acomete principalmente lábio inferior de desenvolvimento lento que tem potencial para se desenvolver em carcinoma epidermóide em lábio (JADOTTE YT e SCHWARTZ RA, 2020). 
Apresenta-se clinicamente como uma lesão ressecada, fissurada e difusa, nessa lesão há perda do limite entre as semi mucosas labiais e a pele, além de edema e eritemas locais, podem ocorrer descamação hiperqueratósica, leucoplasia, áreas inflamatórias juntamente com erosões e ulcerações que atingem parcialmente ou totalmente a área do vermelhão do lábio (CARVALHO GAO, et al., 2020).

Além das características clínicas, essas lesões também possuem em comum a exposição prolongada à luz solar como fator etiológico. O consumo prolongado de álcool e tabaco associado à ação carcinogênica da radiação UV aumenta consideravelmente o risco de desenvolvimento dessa neoplasia. Condições sociodemográficas baixas, suscetibilidade genética e imunossupressão são outros fatores que podem contribuir (SILVA LVDO, 2019).

É importante que, na prática odontológica, o profissional esteja devidamente capacitado, pois cabe ao cirurgião dentista o papel de prevenção, diagnóstico, tratamento e proservação dessa condição clínica, dotado do conhecimento necessário para esse tipo de enfermidade, pois as lesões aparentemente simples podem responder potencialmente progredindo para o câncer (MEDEIROS KF, 2017).

O câncer da boca no Brasil para cada ano do triênio 2020-2022, o número de casos novos estimados é de 11.180 casos em homens e 4010 em mulheres. O que permiti classifica-lo como o quinto tipo de câncer mais comum no sexo masculino e o $13^{\circ}$ mais comum no feminino (INCA, 2020).

As medidas de prevenção ao câncer de lábio englobam desde as orientações à população sobre a etiologia do problema até a importância do uso de protetores solares, chapéus e bonés, assim como explicar a necessidade de reaplicar o protetor solar e o protetor labial depois de atividade intensa devido à perda do efeito protetor (RODRIGUES F, et al., 2016).

É crucial o reconhecimento precoce dessas lesões, pois dessa forma será possível o desenvolvimento de estratégias individuais para cada paciente, e impedir a progressão da doença e promover um tratamento eficaz, aumentando as chances de um prognóstico favorável. Os métodos preventivos são de suma importância, uma vez que, estes podem evitar que indivíduos desenvolvam carcinoma oral. No entanto uma grande parcela de pacientes com queilite actínica desenvolvem carcinoma epidermóide em lábio, devido à falta de prevenção, assim como um diagnóstico e tratamento precoce (CARVALHO GAO, et al., 2020).

Os trabalhadores que diariamente realizam suas atividades laborativas ao ar livre, exercem sua função por mais de três horas e estão mais vulneráveis à exposição crônica UV devido à sua ocupação, dessa forma, esses profissionais são mais propensos a desenvolverem a queilite actínica (CARVALHO GAO, et al., 2019).

Com o intuito de limitar os danos das lesões instaladas e prevenir o surgimento de novas lesões, uma adequada orientação quanto aos malefícios da radiação solar e conscientização do uso de fotoproteção deverão ser fortemente enfatizados pelos profissionais de saúde, em especial pelos cirurgiões-dentistas, principais responsáveis pelo diagnóstico, prevenção e tratamento (BOLDES IP, et al., 2016).

Para a mudança de hábitos e conscientização de toda uma população sobre uma determinada condição ou agravo, são necessárias ações contínuas pelas esferas de governo, além do auxílio das instituições privadas (DE MENESES NE, et al., 2020).

Nesse contexto, a educação em saúde é essencial para promover hábitos de vida saudáveis ao articular saberes técnicos e populares e mobilizar recursos individuais e coletivos. Portanto, para promover a saúde por meio de intervenções educativas deve-se considerar o modo de pensar e viver dos participantes pois, frequentemente, a educação em saúde é confundida com a transmissão de informação em saúde, o que desconsidera o saber popular. Nessa faceta, a educação popular ganha importância, uma vez que os conteúdos e ações partem dos conhecimentos populares e do contexto em que vivem os participantes (MALLMANN DG, et al., 2015).

Esta abordagem reconhece, igualmente, que a educação em saúde tem um papel significativo na determinação do processo saúde-doença, sugerindo a reorientação dos serviços e sistemas de saúde visando à implementação de práticas integrais e o fortalecimento de ações de promoção da saúde (CARVALHO SR e GASTALDO D, 2008). 
As ações de extensões universitárias permitem a formação de profissionais compromissados com a melhoria da realidade social na qual está inserido, além de formar cidadãos preparados para enfrentar as situações mais adversas que surgirem em seu cotidiano profissional. Sabendo-se que trabalhadores praieiros estão expostos a fatores de riscos como exposição solar, sujeitos a condições de trabalho precárias, sem apoio e assistência necessária, foi sugerido uma proposta de intervenção através de ações sociais com a extensão dos conhecimentos adquiridos na faculdade para a população, promovendo-se assim, uma melhoria na qualidade de vida desses trabalhadores para que continuem a desenvolver suas atividades laborais de forma segura e preventiva.

\section{REFERÊNCIAS}

1. ARAÚJO CP, et al. Queilite actínica: um estudo de 35 casos com destaque para os aspectos morfológicos. Rev. Pos. Grad, 2012; 19(1): 21-27.

2. ARAÚJO MCB, COSTA M. Environmental Quality Indicators for Recreational Beaches Classification. Journal of Coastal Research, 2008; 24(6):1439-1449.

3. ARAÚJO MCBD, et al. Análise do comércio formal e informal na Praia de Boa Viagem, Recife, Pernambuco, Brasil. Revista de Gestão Costeira Integrada, 2012; 12(3): 373-388.

4. BARROS CC, et al. A retrospective 11-year study on lip lesions attended at an oral diagnostic service. Medicina oral, patologia oral y cirugia bucal, 2020; 25(3):370.

5. BOLDES IP, et al. Queilite Actínica: Análise Retrospectiva de 29 casos da Clínica de Estomatologia da Odontoclínica Central da Marinha. Revista Naval de Odontologia, 2016; 43(1).

6. CARVALHO GAO, et al. Aspectos clínicos, histopatológicos e tratamento de pacientes diagnosticados com queilite actínica: revisão de literatura. Research, Society and Development,2020; 9(7): e557974407-e557974407.

7. CARVALHO SR, GASTALDO D. Promoção à saúde e empoderamento: uma reflexão a partir das perspectivas crítico-social pós-estruturalista. Ciência \& saúde coletiva, 2008; 13, 2029-2040.

8. DANCYGER A, et al. Malignant transformation of actinic cheilitis: A systematic review of observational studies. Journal of investigative and clinical dentistry, 2018; 9(4):12343.

9. DE MENESES NE, et al. Câncer de boca grau de conhecimento e perfil epidemiológico dos romeiros de Juazeiro Do Norte-CE. Brazilian Journal of Development, 2020; 6(7): 49671-49688.

10. SILVA LVDO. Queilite actínica e carcinoma de células escamosas de lábio: um estudo multicêntrico,MG. Dissertação (Mestrado em Odontologia) - Universidade Federal de Minas Gerais, Belo Horizonte, 2019; 73-73.

11. DOS SANTOS LCO, DE MEDEIROS BATISTA O, CANGUSSU MCT. Caracterização do diagnóstico tardio do câncer de boca no estado de Alagoas. Brazilian Journal of Otorhinolaryngology, 2010; 76(4): 416-422.

12. INCA Instituto Nacional de Câncer (Brasil). Estimativa 2020: incidência de câncer no Brasil. Acesso em 20 de Julho de 2020. Disponível em https://www.inca.gov.br/estimativa/sintese-de-resultados-e-comentarios.

13. JADOTTE YT, SCHWARTZ RA. Solar cheilosis: an ominous precursor: part I. Diagnostic insights. J Am Acad Dermatol, 2012; 66 (2): 173-186.

14. TEIXEIRA ACDOC, et al. Presença de queilite actínica em trabalhadores da zona rural de governador mangabeira atendidos nas unidades básicas de saúde. Textura, 2019; 13(22): 176-189.

15. LUCENA EEDS. (2011). Prevalência e fatores associados a lesões labiais e periorais decorrentes da exposição solar em trabalhadores de praia, Dissertação (Mestrado em Odontologia) - Universidade Federal Rio Grande do Norte, Natal, 2011; $101 \mathrm{f}$.

16. MALLMANN DG, et al. Educação em saúde como principal alternativa para promover a saúde do idoso. Ciência \& Saúde Coletiva, 2015; 20: 1763-1772.

17. MEDEIROS KF. Perfil epidemiológico das principais doenças bucais da colônia de pescadores da cidade de São Soão do Sabugi/RN. Monografia (Graduação) Departamento de Odontologia, Universidade Federal do Rio Grande do Norte, Natal, 2017.

18. NEVILLE B, et al. Patologia Oral e Maxilofacial. 4. ed. Rio de Janeiro: Elsevier, 2016. 912 p.

19. NOVAES TSG, et al. Lesão maligna em lábio: do diagnóstico ao tratamento. ARCHIVES OF HEALTH INVESTIGATION, 2020; 8(9).

20. QUEIROZ LR. Queilite actínica em trabalhadores da construção civil do município de Feira de Santana, Bahia. Dissertação (Mestrado Acadêmico em Saúde Coletiva) - Universidade Estadual de Feira de Santana, Feira de Santana, 2016.

21. QUIRINO MRDS, et al. Avaliação do conhecimento sobre o câncer de boca entre participantes de campanha para prevenção e diagnóstico precoce da doença em Taubaté-SP. Revista de Odontologia da UNESP, 2013; 35(4): 327333.

22. RODRIGUES F, et al. Uso de protetores solares na prevenção do carcinoma de células escamosas de lábio/Use of sunscreens in the prevention of squamous cell carcinoma of the lip/Uso de protectores solares en la prevención del carcinoma de células escamosas de labio. JOURNAL HEALTH NPEPS, 2016; 1(1). 